\title{
Complexidade nos Ambientes Virtuais de Aprendizagem: Utilização dos emoticons nas redes sociais
}

\section{Complexity in Virtual Learning Environments: Use of emoticons on social networks}

\author{
Deise Choti*, Thais Marques** \\ *Pontifícia Universidade Católica do Paraná, **Universidade Positivo
}

\begin{abstract}
Resumo
Atualmente,grande parte da sociedade está conectada por meio de redes sociais. $\mathrm{O}$ meio educacional precisa estar alinhado a essas novas formas de conexão para que o processo ensino/aprendizagem e as relações afetivas advindas dessa conexão encontrem eco num pensamento que privilegie um novo paradigma. A pesquisa é um estudo de caso com abordagem quanti-qualitativa.Este artigo tem como objetivo, o estudo da utilização dos emoticons (emojis) nas redes sociais, percebendo desta forma, como o ser humano em sua complexidade por meio das interações sociais permitem que suas emoções se evidenciem com a utilização desses também chamados ideogramas.

Palavras chave: ambientes virtuais de aprendizagem, redes sociais, paradigma da complexidade, tecnologias.
\end{abstract}

\begin{abstract}
Currently, a large part of society is connected through social networks. The educational environment must be aligned with these new forms of connection so that the teaching / learning process and the affective relationships resulting from this connection find echo in a thought that privileges a new paradigm. The research is a case study with quantitative-qualitative approach. This article aims to study the use of emoticons (emojis) in social networks, perceiving in this way, how the human being in its complexity through social interactions allow its Emotions are evidenced by the use of these so-called ideograms.

Keywords: virtual learning environments, social networks, paradigm of complexity, technologies.
\end{abstract}

\section{Introdução}

Dentre os diversos meios para distribuição de informações disponíveis atualmente, a via eletrônica hoje é o que garante maior disponibilidade, mais fácil acesso aos dados e com o menor custo, pois permite ainda o tráfego de informações bilateralmente.

O computador, tablets e smartphones, tornaram-se ferramentas multifuncionais e eficazes no apoio aos professores para maior dinamismo e melhoria de suas aulas, em especial nos ambientes educativos que contam com a internet, já que permite acesso a um ilimitado banco de dados para pesquisas e disseminação de informações.
Sendo assim, sob o prisma de um pensamento complexo e abordagens de teorias que versem a formação de novos professores, ou mesmo, professores/alunos em formação continuada numa perspectiva inovadora, sobretudo, nos cursos superiores na modalidade semipresencial ou, à distância, encontra-se aqui, nessa pesquisa, eco na inquietação das autoras sobre o tema que vem, dia após dia crescendo por sua importância e pertinência junto a academia, pois de acordo com Choti (2016, p.98),

Daí a necessidade em focalizar as diversas possibilidades de entender a educação e seus mecanismos, numa visão complexa e em seus desdobramentos na prática pedagógica, pois tem como foco a visão de totalidade e da formação integral do ser complexo, entre outras características. O paradigma da complexidade busca a superação da lógica linear e procura atender a uma nova concepção, que tem como eixo articulador a totalidade. A proposta da visão complexa depende do avanço do paradigma da ciência que impulsiona a revisão do processo fragmentado do conhecimento na busca de reintegração do todo.

Para a construção desse artigo, portanto, foi utilizada uma abordagem quanti/qualitativa, que, segundo Demo, (2002, p.35) adverte aos pesquisadores, “[...] não faz nenhum sentido desprezar o lado da quantidade, desde que bem feito". Em vez disso, "[...] só tem a ganhar a avaliação qualitativa que souber se cercar inteligentemente de base empírica, mesmo porque qualidade não é a contradição lógica da quantidade, mas a face contrária da mesma moeda". Ainda, dentro da abordagem quanti/qualitativa, foi feito um estudo de caso. Nesse sentido, segundo Araújo et al. (2008):

$\mathrm{O}$ estudo de caso trata-se de uma abordagem metodológica de investigação especialmente adequada quando procuramos compreender, explorar ou descrever acontecimentos e contextos complexos, nos quais estão simultaneamente envolvidos diversos fatores. Yin (1994, apud ARAÚJO et al. 2008) afirma que esta abordagem se adapta à investigação em educação, quando o 
investigador é confrontado com situações complexas, de tal forma que dificulta a identificação das variáveis consideradas importantes, quando o investigador procura respostas para o "como?" e o "porquê?", quando o investigador procura encontrar interações entre fatores relevantes próprios dessa entidade, quando o objetivo é descrever ou analisar o fenómeno, a que se acede diretamente, de uma forma profunda e global, e quando o investigador pretende apreender a dinâmica do fenómeno, do programa ou do processo.

Pessoas comunicam-se diariamente por meio de novas conexões virtuais em diferentes partes do planeta, tornando essa prática comum no seu dia a dia. Sendo as instituições de ensino parte dessa sociedade, observa-se que a educação necessita favorecer, por meio de suas propostas, disciplinas e pesquisas que possam auxiliar o professor em formação pedagógica inicial, ou continuada.

É nesse processo formativo que se torna imprescindível ao docente conhecer, se interessar, desvendar e exercitar a utilização dessas novas interfaces, no sentido de tornar suas aulas mais dinâmicas e conectadas com o mundo, aproximando-se, assim, das linguagens de seus alunos que, em grande parte, já vivenciam os benefícios e os enfrentamentos oferecidos pela Web 2.0. Diante desse cenário, evidencia-se a necessidade de uma comunicação mais breve, suave, por vezes agradável e também divertida entre seus atores, para que se expressem dessa forma, embora com a "etiqueta" própria para cada momento, mais livre e emotivamente mais próxima de seu interlocutor; essa maneira de escrita pode ser obtida por meio dos emoticons, tema o qual, será tratado no decorrer dessa pesquisa.

\section{Desenvolvimento}

Percebe-se, atualmente, grande interesse por parte dos pesquisadores educacionais pela utilização de recursos encontrados na Web 2.0, no sentido de estar mais próximo a "linguagem" de seus alunos, colegas de trabalho, amigos e até mesmo familiares dentro das redes sociais, ou ainda, em ambientes virtuais de aprendizagem. Nesse sentido, Choti (2016, p. 18), afirma que,

Para tal, acredita-se que a modalidade on-line pode favorecer os docentes no seu aprimoramento profissional, uma vez que considera a aceitação do professor em participar de ambientes virtuais de aprendizagem formais, bem como os não formais (grupos em redes sociais, como o facebook, por exemplo), que o auxiliem num processo mais relevante de ensinar e de aprender.

Desta forma, os resultados dessa pesquisa dão-nos conta de como se pode, mesmo à distância, ou seja, em momentos assíncronos, pessoas demonstrarem suas emoções de forma mais efetiva/afetiva, por meio de ferramentas cada dia mais interativas e amparadas pelo uso da internet que, de acordo com Choti (2016, p.20),

Assistir às televisões cada dia mais interativas, falar aos telefones celulares inteligentes, que por sua vez encontram-se conectados à internet e, muitas vezes, ao substituir os computadores, não só dão aos seus usuários mais mobilidade, como também pressupõem rapidez na tomada de decisões e solicitude de respostas a uma gama de assuntos, quer sejam pessoais, quer sejam profissionais, num curtíssimo espaço de tempo.

Com a evolução das tecnologias, cada vez mais as pessoas buscam reduzir o tempo de seus afazeres, um desses exemplos é a comunicação, onde para se diminuir o tempo de digitação utiliza-se emoticons; sendo assim, segundo Malta (2015, pp. 12 e 13) um emoticon, palavra derivada da junção dos seguintes termos em inglês: emotion (emoção) + icon (ícone) (em alguns casos chamado de smile) é uma sequência de caracteres tipográficos ou, também, uma imagem (usualmente, pequena), que traduz ou quer transmitir o estado psicológico, emotivo, de quem os emprega, por meio de ícones ilustrativos de uma expressão facial. Os emoticons foram criados por si só, com o intuito de facilitar o entendimento para o receptor da mensagem, transformando a escrita da mensagem mais interativa. Segundo Oliveira, Fernandes e Gomes (2016, p.6),

Com a evolução da internet, as interfaces gráficas também foram se modificando, desta forma a partir dos anos 90, novas modificações no formato de texto, possibilitam também mudanças nos emoticons. Essas mudanças sofridas pelos emoticons se deram no Japão, surgindo daí a categoria emojis, que se caracterizam por desenhos, pequenas imagens que substituíram os símbolos que formavam figuras (emoticons).

Diante desse cenário e para atingir seus objetivos, as autoras utilizaram para o desenvolvimento desta investigação, a plataforma Survey Monkey, a qual, segundo os criadores foi designada para soluções de questionários pela web com o intuito de tomada de decisões bem fundamentadas com rapidez e precisão. Em conformidade com os dados retirados do site oficial Survey Monkey, esta plataforma conta com mais de 10 anos de história, sendo utilizada por $100 \%$ das empresas da Fortune 100, entre outras e instituições acadêmicas e organizações. A plataforma é de fácil acessibilidade e bastante intuitiva, sendo possível utilizar de forma gratuita ou, caso necessite de ferramentas mais avançadas, a partir da realização de pagamento.

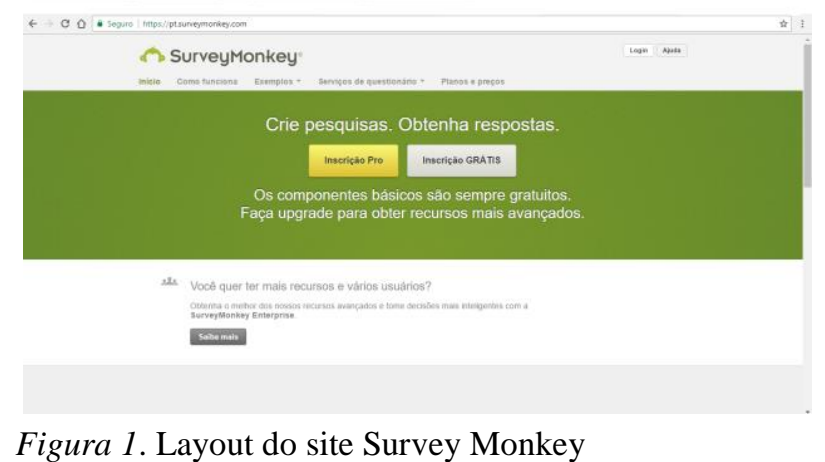

Fonte: <https://pt.surveymonkey.com/> Acesso em: 25 jun./2017.

A figura 1 corresponde ao portal da plataforma Survey Monkey aqui retratada para demonstrar ao leitor como ela se apresenta. 
Dentre outras plataformas que oferecem esta coleta de dados, as autoras utilizaram a Survey Monkey, pois esta oferece gratuitamente dados estatísticos instantaneamente após a colaboração do público alvo, o que facilita a visualização das respostas adquiridas.

\section{Fases da Pesquisa}

$\mathrm{O}$ interesse em pesquisar sobre o assunto vai de encontro ao que se vive no dia-a-dia pois, percebe-se uma grande receptividade e o crescimento da aceitação de um público heterogêneo que passa a ver nessas interfaces, não só a rapidez, bem como, a complexidade existente no ser humano para que se possa demonstrar alguns de seus mais sinceros sentimentos(via emoticons), e encontra nesses hideogramas, meios facilitadores para sua comunicação diária; nesse sentido, o público alvo dessa investigação retrata essa realidade ao mostrar diferentes ideias sobre o assunto, pois teve uma faixa etária abrangente que destacou seus participantes entre 17 a 60 anos, sendo eles alunos da graduação, pós-graduação, mestrandos, doutorandos, professores, professores doutores, ou ainda, professores em formação continuada. Esta pesquisa foi realizada a partir de um questionário com 61 participantes dentro de algumas redes sociais e ambientes virtuais de aprendizagem.

Com a finalidade de compreender o seu público alvo foram realizadas perguntas de forma fechada, as quais foram convertidas em dados estáticos e transformadas em gráficos que serão apresentados para um melhor entendimento.

- $1^{\circ}$ Grupo de Perguntas: Perguntas relacionadas a características dos entrevistados

Como demonstrado no gráfico 1, a maioria dos entrevistados tem idade entre 17 a 27 anos.

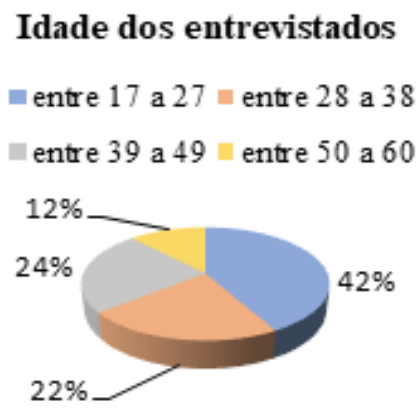

Gráfico 1. Idade: Faixa etária do grupo entrevistado Fonte: As autoras, com base nos dados coletados.

A partir da análise do gráfico, percebe-se que a faixa etária entre 17 a 27 anos é a maioria enquanto que a faixa entre 50 a 60 anos a minoría.
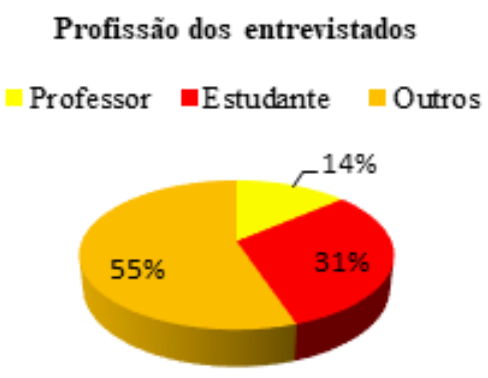

Gráfico 2. Profissão dos entrevistados

Fonte: As autoras, com base nos dados coletados.

Percebe-se que os entrevistados em sua maioria são professores em formação continuada de várias áreas profissionais (55\%), e os estudantes em si, contemplam a faixa de $31 \%$. Este é um dado interessante, pois demonstra que o professor está realmente empenhandose para estar cada dia mais próximo da realidade de seus alunos.

- $2^{\circ}$ Grupo de Perguntas: Perguntas relacionadas a utilização de redes sociais e emoticons.

Como apresentado no gráfico 3, a rede social WhatsApp é utilizada por $100 \%$ dos entrevistados.

\section{Redes sociais mais utilizadas}

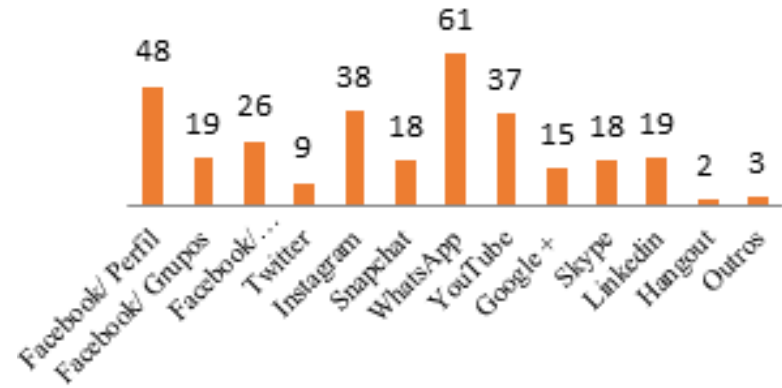

Gráfico 3. Quais redes sociais o entrevistado mais utiliza Fonte: As autoras, com base nos dados coletados.

As respostas para esta questão já haviam sido prédefinidas, sendo apenas necessário que o respondente selecionasse quais mais utilizava, após verificação do gráfico percebe-se que o WhatsApp é utilizado por todos, e o Facebook na forma Perfil o segundo mais utilizado com 48 pessoas.

O gráfico 4 tem como finalidade apresentar a utilização ou não dos emoticons no cotidiano dos entrevistados.

\section{Utilização dos emoticons}

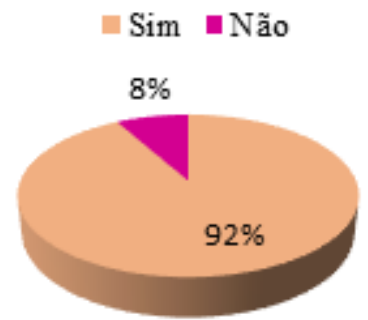

Gráfico 4. Utilização dos emoticons

Fonte: As autoras, com base nos dados coletados. 
Ao analisar o gráfico 4, percebe-se que os respondentes em sua maioria, ou seja $92 \%$ utilizam os emoticons, ou seja, esta forma de expressar-se é muito importante para os sujeitos da pesquisa.

O gráfico 5 tem como objetivo explicar a finalidade com que estes emoticons são utilizados, quando os entrevistados fazem uso deste hideograma.

\section{Finalidade da utilização de emoticons}

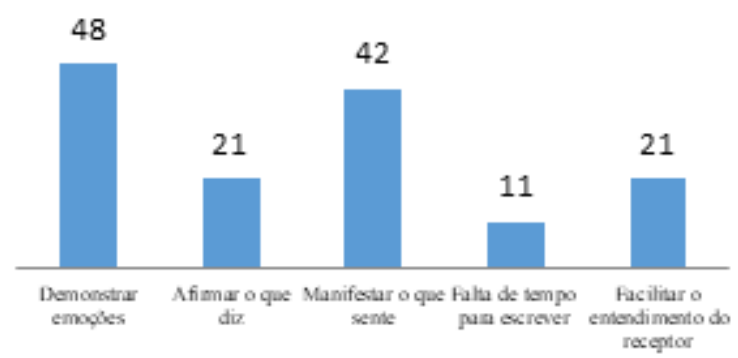

Gráfico 5. Finalidade da utilização de emoticons. Fonte: As autoras, com base nos dados coletados.

As respostas apresentadas nesta questão já haviam sido pré-estabelecidas, sendo apenas necessário que o respondente selecionasse as que julgasse mais compatível com seu cotidiano. Demonstrar afeições e manifestar o que sente, foram escolhidas como as de maior expressividade e utilização para os respondentes.

O gráfico 6 refere-se a representação dos hideogramas em relação aos sentimentos expressados por ele.

Representação de sentimentos

\section{$\square$ Nada (apenas para enf eitar) $\square$ Pouco $\square$ Muito}

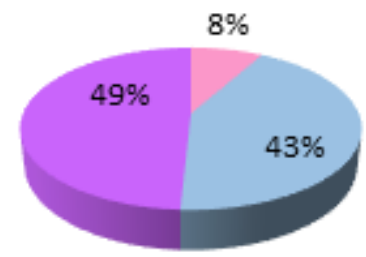

Gráfico 6. O quanto representa os sentimentos em relação a utilização dos emoticons.

Fonte: As autoras, com base nos dados.

Percebe-se que praticamente metade dos respondentes (49\%) afirma que quando utiliza os hideogramas, estes representam em muito os sentimentos expressados, ou seja, a maioria utiliza os emoticons, para de certa forma, reforçarem as suas emoções quando se expressam.

O gráfico 7 teve por objetivo demonstrar se, caso o respondente necessitasse usar um emoticon em sua rede social, e procurasse por um sentimento específico, havia encontrado, ou não, essa opção.

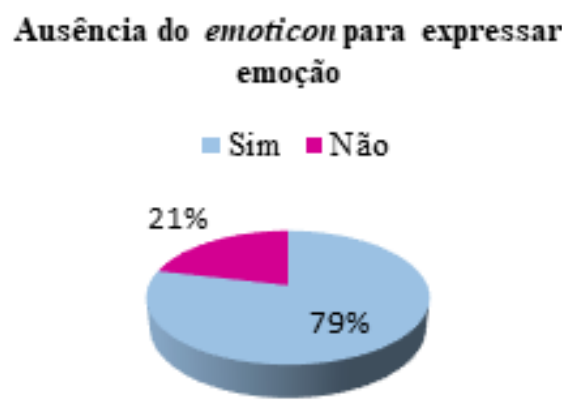

Gráfico 7. Ausência do emoticon para expressar emoção. Fonte: As autoras, com base nos dados coletados.

Ao analisar o gráfico 7 percebe-se que os respondentes em sua maioria (79\%) no seu cotidiano, depararam-se com a ausência de um hideograma adequado para expressar uma emoção, pois o mesmo não estava presente na lista disponível, a qual, o usuário tinha acesso em sua rede social.

Diante dos dados coletados a partir do questionário e que se evidenciam por meio dos gráficos, conclui-se que com a modernidade do nosso cotidiano permita que as pessoas utilizem mais das tecnologías e adaptem seu cotidiano a elas, um caso interessante foi o dado obtido a partir das profissões, o qual mostrou que professores em educação continuada estão utilizando cada vez mais dessas interfaces. Os respondentes, utilizam-se dos emoticons com diferentes finalidades em suas redes sociais sendo a mais comum para demonstrar o que sentem, as quais em algum momento não possuem todos os hideogramas necessários para expressar de forma fidedigna a emoção/sentimento de seus usuários.

\section{Considerações Finais}

Por meio dessa investigação e com o objetivo de construir conhecimentos pautados num paradigma da complexidade, são muito bem-vindas as redes sociais que, em algumas situações tornam-se as salas de aula desses novos tempos, em que o ser humano passa a ser visto em sua totalidade, aceitando e sendo aceito ao respeitar emotividades, fragilidades, pontos fortes, e habilidades diferenciadas, sendo respeitado e dando demonstrações de como também respeitar o outro por meio de linguagens mais objetivas e práticas (com a utilização de emoticons, por exemplo), mas não menos eficazes no que tange a demonstrar seus sentimentos. Observou-se, ainda, o grau de interesse desses alunos (futuros docentes) e professores para utilizarem-se das inúmeras possibilidades disponíveis na utilização de recursos encontrados nas mídias e redes sociais dentro da web 2.0, no sentido de potencializar o aprendizado. Percebeu-se, também, que há muito o que aprender nessa interrelação discente/docente no enfrentamento de uma sala de aula, quer seja em um espaço físico e síncrono, quer seja em ambientes virtuais de aprendizagem formais ou não formais (como grupos nas redes sociais). Nesse processo, portanto, vislumbrou-se a produção de um conhecimento rico, inovador e que poderá auxiliar os envolvidos nesse processo de formar e ser formado, levando a reflexões críticas, que modifiquem as maneiras 
de atualizar-se que caracterizam a ação do futuro professor e do professor em exercício, sujeitos dessa pesquisa; independentemente do nível educacional que esteja ocupando, esse profissional formador ou em formação precisa ter um olhar renovado, ético, reflexivo e atual em suas práxis, para que a cada dia mais possa contribuir para uma docência compatível com as práticas paradigmáticas numa visão complexa e inovadora, esperadas pela sociedade do século XXI.

\section{Referencias}

Araújo, Cidália et al. Estudo de caso: métodos de investigação em educação. Instituto de Educação e Psicologia, Universidade do Minho, 2008. Disponível em:

http://www.unisc.br/portal/images/stories/a_unisc/estr utura_administrativa/nupes/estudo_caso.pdf >. Acesso em: 07 mar. 2017.

Choti, Deise Maria Marques. Formação Pedagógia de professores universitários numa visão paradigmática inovadora: A utilização de recursos encontrados na Web 2.0. Disponível em: <http://www.biblioteca.pucpr.br/pergamum/biblioteca /img.php?arquivo=/00005e/00005edd.pdf $>$. Acesso em: 23 maio 2017.

Demo, P. Avaliação qualitativa. 7.ed. Campinas: Autores Associados, 2002.

Malta, Aline Rodrigues Malta. Formalidade e informalidade na linguagem do gênero Chat: o uso de emoticons. Disponível em: http://www.nehte.com.br/simposio/anais/Anais-

Hipertexto-

2015/Formalidade\%20e\%20informalidade.pdf $>$.

Acesso em 27 maio 2017.

Oliveira, Letícia de; FERNANDES,Patrícia Damasceno; GOMES, Nataniel dos Santos. Leituras e emojis em um mundo globalizado. Disponível em: <http://www.filologia.org.br/rph/ANO22/66supl/0083 .pdf $>$. Acesso em 30 maio 2017.

PLATAFORMA SURVEY MONKEY. Disponível em: $<$ https://pt.surveymonkey.com/ >. Acesso em 24 maio 2017 